\title{
Evaluating Bilingual Teaching Quality for NC Based on AHP-Fuzzy Comprehensive Evaluation Approach
}

\author{
Dongfang $\mathrm{HU}^{1,}$, Yuanhao $\mathrm{Jl}^{1, \mathrm{~b}}$ \\ ${ }^{1}$ School of Mechantronics Engineering, Henan University of Science and Technology, Luoyang, \\ 471003, China \\ aemail: hdf@haust.edu.cn, bemail: justin910919@163.com
}

Keywords: Numerical Control Technology; Bilingual Teaching; AHP; Fuzzy Mathematics; Evaluation

\begin{abstract}
A reasonable evaluation approach of bilingual teaching quality for numerical control technology is lacked at present. We build the evaluation model of bilingual teaching quality for numerical control technology based on the combination of analytic hierarchy process and fuzzy mathematical. Specifically, after determining the primary indexes and sub-indexes, the weight of each evaluation index is determined by AHP. Then, fuzzy comprehensive evaluation approach is established. Finally, the bilingual teaching quality is evaluated based on the model, and the direction and suggestions are put forward for the reform of bilingual teaching of numerical control technology according to the evaluation results.
\end{abstract}

\section{Introduction}

In recent years, bilingual teaching [1] has been practiced in more and more specialized courses in universities. The course of numerical control technology is developed in engineering colleges as a bilingual teaching demonstration course. Due to the lack of the experience in bilingual teaching filed and the influence of many factors, the quality of NC bilingual teaching in many colleges and universities has not achieved the desired goal. An accurate and fair teaching evaluation can reflect the teachers' teaching level, obtain comprehensive message of feedback, and improve the quality of teaching. It can points out that the science direction of reform in the future and promote the bilingual teaching mode of CNC to be perfect [2].

At present, the network evaluation approach is generally used to evaluate the quality of bilingual teaching in engineering colleges [3]. The total score can be calculated through the weight assignment of evaluation factors, then according to the total score to evaluate the quality of CNC bilingual teaching. As far as NC bilingual teaching, the traditional evaluation approaches mainly have the following deficiencies:

a) Bilingual teaching is a kind of exploration and innovation in the teaching mode, the traditional teaching evaluation factors are not very suitable, which need to take the special evaluation factors into account.

b) It is easily affected by the subjective factors of the participants using the questionnaire to get the weight of the evaluation indexes, which cannot accurately reflect the weight of evaluation index, exaggerate or reduce the effect of some indicators. So the weighting result has poor objectivity.

c) The weight of the evaluation index is judged by expert group based on the experience, which has a certain degree of subjectivity. The weight of each evaluation index has a greater deviation compared with the actual situation because of lacks quantitative analysis as a basis.

d) It is difficult to show how the evaluation course is in each aspect as the comprehensive result of evaluation is abstract.

To sum up, the quality of bilingual teaching for NC is lack of proper evaluation system. It is urgent that we need a reasonable evaluation approach to reflect the quality of bilingual teaching for NC in university. Then, the comprehensive evaluation approach is established, which combine fuzzy comprehensive evaluation approach [4] with the approach of AHP [5]. It takes each expert subjectivity on weight value of evaluation index into account. Moreover, the new analysis approach 
is adopted to calculate the index weight using the analytic hierarchy process (AHP). Finally, the quality for bilingual teaching of NC is evaluated by using the approach of the fuzzy comprehensive evaluation.

\section{Establish the quality evaluation model for bilingual teaching of NC}

Establish evaluation indexes for teaching quality:

Many complex factors that affect the quality of NC bilingual teaching in Colleges and universities involve many aspects [6]. According to the special mode of numerical control bilingual teaching, the reasonable evaluation factors in the evaluation model are analyzed and determined. We determine the content of the evaluation index from five aspects of teaching mode, teaching condition, teaching attitude, classroom teaching and after-class teaching. After determining the relationship between the quality evaluation factors for bilingual teaching of NC, the evaluation indexes of teaching quality is established as shown in table 1.

Table 1. The evaluation indexes of teaching quality

\begin{tabular}{|c|c|}
\hline Primary indexes & Sub-indexes \\
\hline \multirow{3}{*}{ Teaching mode $\left(\mathrm{U}_{1}\right)$} & English teaching $\left(\mathrm{U}_{11}\right)$ \\
\hline & English and Chinese contrast $\left(\mathrm{U}_{12}\right)$ \\
\hline & Chinese dominant, and English auxiliary $\left(\mathrm{U}_{13}\right)$ \\
\hline \multirow{4}{*}{ Teaching condition $\left(\mathrm{U}_{2}\right)$} & Faculty $\left(\mathrm{U}_{21}\right)$ \\
\hline & English level of students $\left(\mathrm{U}_{22}\right)$ \\
\hline & Selection of textbooks $\left(\mathrm{U}_{23}\right)$ \\
\hline & Hardware facilities $\left(\mathrm{U}_{24}\right)$ \\
\hline \multirow{3}{*}{ Teaching attitude $\left(\mathrm{U}_{3}\right)$} & Full preparation, teaching seriously $\left(\mathrm{U}_{31}\right)$ \\
\hline & Concern and strict requirements of students $\left(\mathrm{U}_{32}\right)$ \\
\hline & Listen to the views of students, communicate with others in teaching methods $\left(\mathrm{U}_{33}\right)$ \\
\hline \multirow{4}{*}{ Classroom teaching $\left(\mathrm{U}_{4}\right)$} & The content is rich, the viewpoint is correct $\left(\mathrm{U}_{41}\right)$ \\
\hline & Focus on the outstanding, reasonably detailed in class $\left(\mathrm{U}_{42}\right)$ \\
\hline & Combining the development of subject, introducing the latest achievements $\left(\mathrm{U}_{43}\right)$ \\
\hline & Encourage the interaction between teachers and students, improve the students' learning interest $\left(\mathrm{U}_{44}\right)$ \\
\hline \multirow{3}{*}{ After-class teaching $\left(\mathrm{U}_{5}\right)$} & Homework of NC in English $\left(\mathrm{U}_{51}\right)$ \\
\hline & Discussion of curriculum design in English $\left(\mathrm{U}_{52}\right)$ \\
\hline & Examination of course is combined English written with spoken $\left(\mathrm{U}_{53}\right)$ \\
\hline
\end{tabular}

Calculate index weight by the method of AHP:

AHP is a multi-objective decision analysis method which combine qualitative analysis with quantitative analysis. The evaluation indexes are quantified to obtain the weight of each evaluation index by this method.

STEP1: The key step of the AHP method is to construct the comparison judgment matrix. The same layer indicators which impacts on the quality of teaching are compared with each other based on the influence on higher layer indicators, and the judgment matrix can be given. The comparison of factors in the same layer are paired, and a certain judgment on the relative importance of the factors in each layer can be given. The basis or source of these values is generally based on experts demonstrate the importance of various indicators, which is professional, objective and comprehensive. The method of 1-9 scale [7] is used to compare the evaluation indexes of all levels, and the majority principle is used to construct the judgment matrix $\boldsymbol{U}$. The assignment criteria of the elements in the judgment matrix $\boldsymbol{U}$ is shown in table 2.

Table 2. Scale definition

\begin{tabular}{cc}
\hline Scale & Definition \\
\hline 1 & Equal importance \\
3 & moderate importance \\
5 & strong importance \\
7 & demonstrated importance \\
9 & extreme importance \\
$2,4,6,8$ & Intermediate Values
\end{tabular}

STEP2: After completion of the judgment matrix, the calculation of index weight as well as 
consistency test are required. The judgment matrix is normalized to calculate the maximum eigenvalue $\lambda_{\max }$ and feature vector $\boldsymbol{W}$. Then, we can obtain $\overline{\boldsymbol{W}}$ which is single hierarchy weight. The ratio of CI which reflect the consistency of the index and the correction coefficient RI are introduced to test the consistency of judge of appraiser. If CR is smaller than 0.1, the judgment matrix is satisfied with the consistency. Otherwise, it is required to adjust the initial value in the judgment matrix. The value of the correction factor RI is shown in Table 3.

Table 3. Random index (RI) of random matrices

\begin{tabular}{ccccccccc}
\hline $\mathrm{N}$ & 3 & 4 & 5 & 6 & 7 & 8 & 9 & 10 \\
\hline $\mathrm{RI}$ & 0.58 & 0.9 & 1.12 & 1.24 & 1.32 & 1.41 & 1.45 & 1.49 \\
\hline
\end{tabular}

Evaluation of fuzzy comprehensive:

STEP1: The set of evaluation index is determined as follows:

$$
\begin{aligned}
& U=\left\{U_{1} U_{2} U_{3} U_{4} U_{5}\right\} \quad U_{1}=\left\{U_{11} U_{12} U_{13}\right\} \quad U_{2}=\left\{U_{21} U_{22} U_{23} U_{24}\right\} \quad U_{3}=\left\{U_{31} U_{32} U_{33}\right\} \\
& U_{4}=\left\{U_{41} U_{42} U_{43} U_{44}\right\} \quad U_{5}=\left\{U_{51} U_{52} U_{53}\right\}
\end{aligned}
$$

STEP2: Establish the set of comments. The set of fuzzy evaluation grade V= (V1, V2, V3, V4, V5) is intercalated. It is divided into five evaluation levels, including higher quality, high quality, general quality, low quality, and lower quality. In order to facilitate the calculation, the different grades assignment of evaluation as shown in table 4.

Table 4. Classification of evaluation grades

\begin{tabular}{ccc}
\hline evaluation grade & percentile interval & assign value \\
\hline higher quality & $90-100$ & 95 \\
high quality & $80-89$ & 85 \\
general quality & $70-79$ & 75 \\
low quality & $60-69$ & 65 \\
lower quality & Less than 60 & 30 \\
\hline
\end{tabular}

STEP3: Establish fuzzy evaluation matrix of $\boldsymbol{R}$. Firstly, the evaluation index are judged based on the set of fuzzy evaluation grade. Then, the degree of membership can be determined as $\boldsymbol{r}_{i j}(i=1$, $2, \ldots, \mathrm{n} ; j=1,2, \ldots, \mathrm{m})$. For every evaluation index, there is a corresponding vector for membership degree as $\boldsymbol{R}=\left\{r_{\mathrm{i} 1}, r_{\mathrm{i} 2}, r_{\mathrm{i} 3}, \ldots, r_{\mathrm{im}}\right\}$. Then, the value of each membership degree can be obtained, which can get the evaluation matrix $\boldsymbol{R}$ as follows:

$$
\boldsymbol{R}=\left[\begin{array}{cccc}
r_{11} & r_{12} & \cdots & r_{1 m} \\
\vdots & \vdots & \vdots & \vdots \\
r_{n 1} & r_{n 2} & \cdots & r_{n m}
\end{array}\right]
$$

STEP4: By using the synthetic operation of the fuzzy matrix, a comprehensive evaluation vector is obtained as follows:

$$
\boldsymbol{B}=\boldsymbol{W} \cdot \boldsymbol{R}=\left(b_{1}, b_{2}, \cdots, b_{m}\right)
$$

In the formulation, the parameter " $W$ " is the set of index weight, which is obtained by AHP. And “.” is representation of fuzzy operator. The method of weight assignment used in this paper is $\mathrm{M}(\cdot, \oplus)$ as follows:

$$
\boldsymbol{B}_{j}=\sum_{i=1}^{n} A_{i} \cdot \boldsymbol{R}_{i, j}
$$

The vector of fuzzy comprehensive evaluation should adopt normalization method if $\sum_{i=1}^{m} \boldsymbol{B}_{i} \neq 1$. Finally, the comprehensive evaluation results can be obtained according to the evaluation vector.

\section{Quality evaluation of bilingual teaching of numerical control}

STEP1: Calculate index weight by the method of AHP as follows:

In view of the special evaluation factors for bilingual teaching of NC, the comparison judgment matrix is constructed and the index weight is calculated. The values of comparison judgment matrix is derived from ten experts. All evaluation indexes are given the quantitative values for relative importance based on the method of 1-9 scale. 
The judgment matrix of the primary indexes and sub-indexes as follows:

$$
\begin{aligned}
& \boldsymbol{U}=\left[\begin{array}{ccccc}
1 & 1 / 5 & 1 / 2 & 1 / 4 & 1 / 3 \\
5 & 1 & 4 & 1 / 3 & 1 / 2 \\
2 & 1 / 4 & 1 & 1 / 2 & 1 / 3 \\
4 & 3 & 2 & 1 & 2 \\
3 & 2 & 3 & 1 / 2 & 1
\end{array}\right] \boldsymbol{U}_{1}=\left[\begin{array}{ccc}
1 & 1 / 3 & 1 / 2 \\
3 & 1 & 2 \\
2 & 1 / 2 & 1
\end{array}\right] \boldsymbol{U}_{2}=\left[\begin{array}{cccc}
1 & 2 & 3 & 5 \\
1 / 2 & 1 & 2 & 3 \\
1 / 3 & 1 / 2 & 1 & 2 \\
1 / 5 & 1 / 3 & 1 / 2 & 1
\end{array}\right] \\
& \boldsymbol{U}_{3}=\left[\begin{array}{ccc}
1 & 2 & 5 \\
1 / 2 & 1 & 2 \\
1 / 5 & 1 / 2 & 1
\end{array}\right] \boldsymbol{U}_{4}=\left[\begin{array}{cccc}
1 & 5 & 4 & 3 \\
1 / 5 & 1 & 3 & 2 \\
1 / 4 & 1 / 3 & 1 & 1 / 2 \\
1 / 3 & 1 / 2 & 2 & 1
\end{array}\right] \boldsymbol{U}_{5}=\left[\begin{array}{ccc}
1 & 5 & 3 \\
1 / 5 & 1 & 1 / 3 \\
1 / 3 & 3 & 1
\end{array}\right]
\end{aligned}
$$

Firstly, after normalization for the judgment matrix of the primary indexes, we can get $\bar{U}$ as follows:

$$
\overline{\boldsymbol{U}}=\left[\begin{array}{ccccc}
0.0667 & 0.031 & 0.0476 & 0.0968 & 0.08 \\
0.3333 & 0.155 & 0.3810 & 0.1290 & 0.12 \\
0.1333 & 0.0388 & 0.0952 & 0.1935 & 0.08 \\
0.2667 & 0.4651 & 0.1905 & 0.3871 & 0.48 \\
0.2 & 0.3101 & 0.2857 & 0.1935 & 0.24
\end{array}\right]
$$

Every row of $\boldsymbol{U}$ is added to obtain $\boldsymbol{W}$. After normalization, $\overline{\boldsymbol{W}}$ is the set of index weight can be obtained as follows:

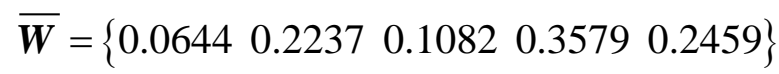

The largest eigenvalue is judged in matrix is as follows:

$\lambda_{\text {max }}=5.3442$

And the consistency index of matrix is judged as follows:

$\frac{\lambda_{\max }-n}{n-1}=\frac{5.3442-5}{5-1}=0.086$

Then, the ratio of randomly consistent is as follows:

$$
C R=\frac{C I}{R I}=\frac{0.086}{1.12}=0.0768<0.1
$$

Therefore, the weight coefficient distribution is reasonable.

Also, we can get the set of index weight for sub-indexes and check it by this method. The results as shown below:

$$
\begin{aligned}
& \overline{W_{1}}=\left\{\begin{array}{lll}
0.1638 & 0.5390 & 0.2973
\end{array}\right\} \quad \overline{W_{2}}=\left\{\begin{array}{llll}
0.4824 & 0.2718 & 0.1575 & 0.0883
\end{array}\right\} \\
& \overline{W_{3}}=\left\{\begin{array}{lll}
0.5949 & 0.2766 & 0.1285
\end{array}\right\} \quad \overline{W_{4}}=\left\{\begin{array}{llll}
0.5385 & 0.2165 & 0.0915 & 0.1535
\end{array}\right\} \\
& \overline{W_{5}}=\left\{\begin{array}{lll}
0.6333 & 0.1062 & 0.2605
\end{array}\right\}
\end{aligned}
$$

STEP2: The fuzzy evaluation matrix $\boldsymbol{R}$ is constructed based on the established evaluation set. Inviting 80 students from class, which has bilingual teaching of $\mathrm{NC}$, make a comprehensive evaluation to each index. The result of evaluation is shown in table 5 from investigation and assessment in teaching model, teaching conditions, teaching attitude, classroom teaching, and after-class teaching. 
Table 5. Evaluation results of sub-indexes

\begin{tabular}{cccccc}
\hline \multirow{2}{*}{ Sub-indexes } & \multicolumn{5}{c}{ Evaluation results } \\
\cline { 2 - 6 } & $\mathrm{V}_{1}$ & $\mathrm{~V}_{2}$ & $\mathrm{~V}_{3}$ & $\mathrm{~V}_{4}$ & $\mathrm{~V}_{5}$ \\
\hline $\mathrm{U}_{11}$ & 11 & 15 & 22 & 27 & 5 \\
$\mathrm{U}_{12}$ & 42 & 25 & 13 & 0 & 0 \\
$\mathrm{U}_{13}$ & 12 & 10 & 19 & 31 & 8 \\
$\mathrm{U}_{21}$ & 33 & 20 & 21 & 6 & 0 \\
$\mathrm{U}_{22}$ & 18 & 22 & 26 & 12 & 2 \\
$\mathrm{U}_{23}$ & 26 & 15 & 28 & 11 & 0 \\
$\mathrm{U}_{24}$ & 25 & 20 & 19 & 9 & 7 \\
$\mathrm{U}_{31}$ & 23 & 35 & 12 & 10 & 0 \\
$\mathrm{U}_{32}$ & 35 & 23 & 20 & 2 & 0 \\
$\mathrm{U}_{33}$ & 12 & 20 & 35 & 13 & 0 \\
$\mathrm{U}_{41}$ & 45 & 21 & 14 & 0 & 0 \\
$\mathrm{U}_{42}$ & 31 & 20 & 16 & 13 & 0 \\
$\mathrm{U}_{43}$ & 16 & 22 & 25 & 17 & 0 \\
$\mathrm{U}_{44}$ & 23 & 31 & 16 & 10 & 0 \\
$\mathrm{U}_{51}$ & 34 & 35 & 11 & 0 & 0 \\
$\mathrm{U}_{52}$ & 21 & 22 & 15 & 18 & 4 \\
$\mathrm{U}_{53}$ & 39 & 30 & 11 & 0 & 0 \\
\hline
\end{tabular}

The evaluation matrix $\boldsymbol{R}$ is obtained according to table 5 as follows:

$$
\begin{aligned}
& \boldsymbol{R}_{1}=\left[\begin{array}{ccccc}
0.1375 & 0.1875 & 0.275 & 0.3375 & 0.0625 \\
0.5255 & 0.3125 & 0.1625 & 0 & 0 \\
0.15 & 0.125 & 0.2375 & 0.3875 & 0.1
\end{array}\right] \quad \boldsymbol{R}_{2}=\left[\begin{array}{ccccc}
0.3882 & 0.2353 & 0.2471 & 0.0706 & 0.0588 \\
0.225 & 0.275 & 0.325 & 0.15 & 0.025 \\
0.2955 & 0.1705 & 0.3182 & 0.125 & 0.0909 \\
0.3125 & 0.25 & 0.2375 & 0.1125 & 0.0875
\end{array}\right]
\end{aligned}
$$

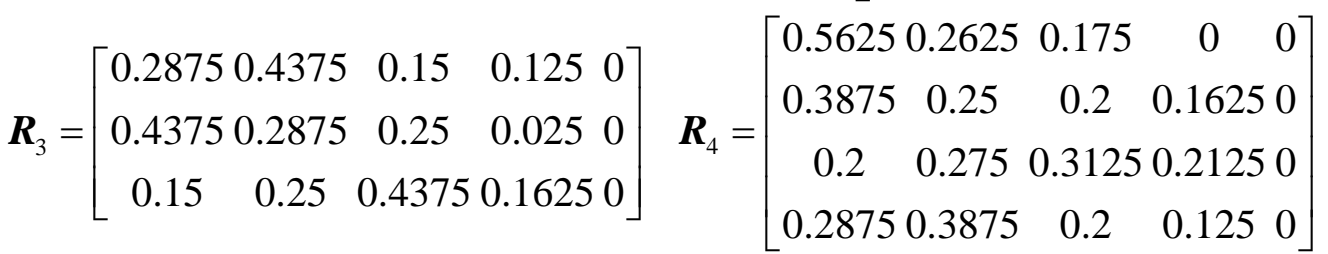

$$
\begin{aligned}
& \boldsymbol{R}_{5}=\left[\begin{array}{ccccc}
0.425 & 0.4375 & 0.1375 & 0 & 0 \\
0.2625 & 0.275 & 0.1875 & 0.225 & 0.05 \\
0.4875 & 0.375 & 0.1375 & 0 & 0
\end{array}\right]
\end{aligned}
$$

STEP3: According to the weight assignment as well as these five evaluation matrices of sub-indexes, we can get the single factor evaluation vector $\boldsymbol{B}$ of sub-index. The specific process of calculation is as follows:

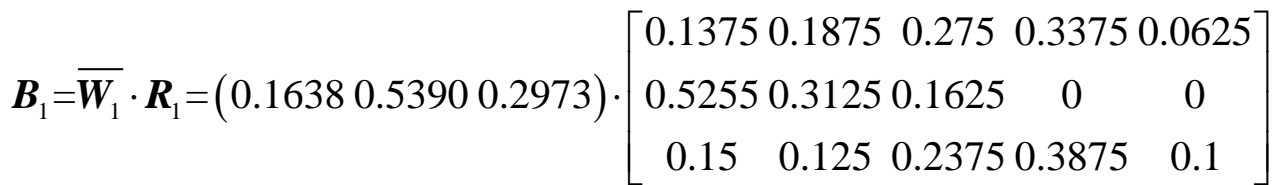

$$
\begin{aligned}
& =\left(\begin{array}{lll}
0.35010 .23630 .2032 & 0.17050 .04
\end{array}\right) \\
& \boldsymbol{B}_{2}=\overline{\boldsymbol{W}_{2}} \cdot \boldsymbol{R}_{2}=\left(\begin{array}{lll}
0.3226 & 0.23720 .27860 .1044 & 0.0572
\end{array}\right) \\
& \boldsymbol{B}_{3}=\overline{\boldsymbol{W}_{3}} \cdot \boldsymbol{R}_{3}=\left(\begin{array}{l}
0.31130 .37190 .21460 .10220
\end{array}\right) \\
& \boldsymbol{B}_{4}=\overline{\boldsymbol{W}_{4}} \cdot \boldsymbol{R}_{4}=\left(\begin{array}{l}
0.44920 .28010 .19680 .07380
\end{array}\right)
\end{aligned}
$$

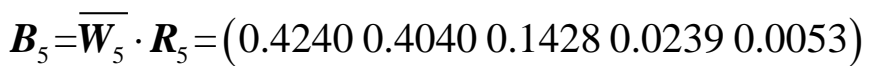

STEP4: The single factor evaluation vector $\boldsymbol{B}$ of sub-index are combined into a comprehensive evaluation matrix. Then the primary index comprehensive evaluation vector is obtained by carrying out the fuzzy comprehensive evaluation. 


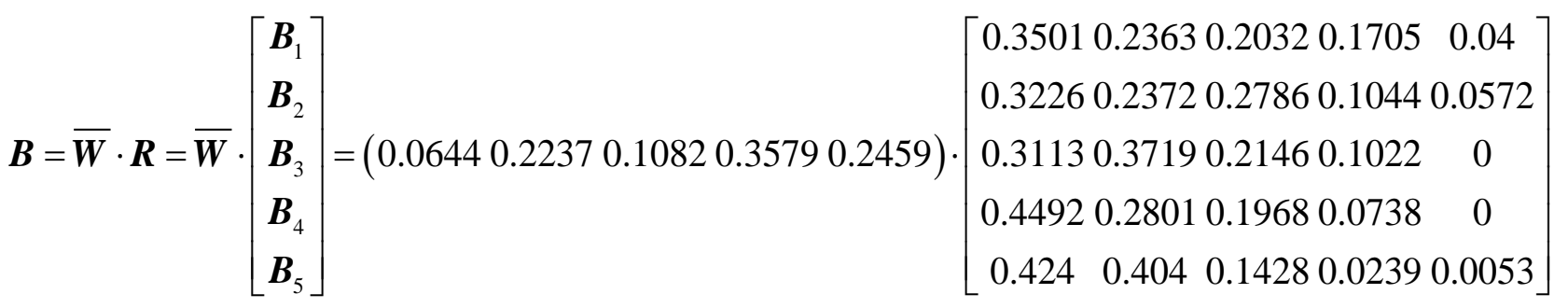

$=(0.39340 .30810 .20420 .07770 .0167)$

Quality evaluation for characteristics bilingual teaching of $\mathrm{NC}$ in our school can be seen by the comprehensive evaluation vector. The overall distribution of evaluation is shown in Figure 1. Finally, according to the comprehensive evaluation vector, we can get the comprehensive evaluation of the quality of the bilingual teaching in our school. The score of the comprehensive evaluation for overall as well as primary indexes as shown in figure 2, which can be calculated based on evaluation vector and assign value.
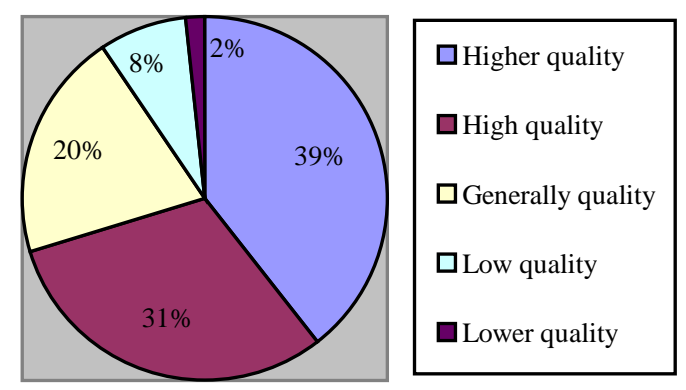

Fig.1. Distribution of quality evaluation

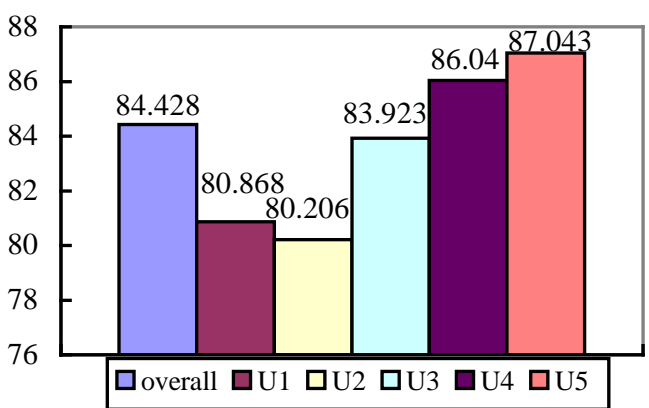

Fig.2. Comprehensive score of teaching quality

\section{Conclusion}

The overall evaluation of the quality for bilingual teaching is 84.428 , which indicates that there is much space to improve in our school. The teaching mode and the condition of teaching can barely reach a higher level from the evaluation of five primary indexes on the quality of bilingual teaching. It is the reform direction which needs to be strengthened in the future. The teaching mode can develop its characteristic in order to adapt the situation of the university itself. Some aspects are given more attention, such as teaching conditions in University, the quality of teachers and students, and the teaching hardware facilities.

\section{Acknowledgement}

The authors gratefully acknowledge the project for education and teaching reform of Henan University of Science and Technology (No. 2012N-007) and the national superior course and bilingual teaching demonstration course for financial support of this research work.

\section{References}

[1] Tan Duo-jiao. Bilingual teaching: The strategic choice of international of higher education in China [J]. Education Research, 2012 (11) 83-86.

[2] Qu Yan, Wang Zhen-bo, Wang Jian-jun. Research status quo of bilingual teaching mode in Chinese Universities [J]. Higher Education of Sciences, 2014 (2) 104-108.

[3] Dong Yu-xin, Yin Gui-sheng. The research and practice of bilingual teaching mode and evaluation mechanism in universities and colleges [J]. Exploration of Higher Education, 2007 S1 30-31+33.

[4] Zhang Wen-dan, Lu Jian, Zhang Yi. Comprehensive Evaluation Index System of Low Carbon 
Road Transport Based on Fuzzy Evaluation Method [J]. Procedia Engineering, 2016137.

[5] AlirezaRiahi, MahdiMoharrampour. Evaluation of Strategic Management in Business with AHP Case Study: PARS House Appliance[J]. Procedia Economics and Finance, 201636.

[6] Long Guo-zhi. Analysis on the present situation of bilingual teaching in Universities in China [J]. Reform \& Opening, 2011 (4) 173-174.

[7] Saaty T L. The analytic hierarchy process: Planning, priority setting, resource Allocation. McGraw-Hill, NY, USA [M]. The Analytic Hierarchy Process: Planning, Priority Setting, Resource Allocation. 1980. 